\title{
AS SENTENÇAS CLIVADAS NO PORTUGUÊS FALADO DO RIO DE JANEIRO
}

\author{
MARIA LUIZA BRAGA
}

\begin{abstract}
"Ricardo Reis rebusca na memória fragmentos de versos que já levam vinte anos de feitos... E há um momento em que duvida se teráo mais sentido as odes completas aonde os foi buscar do que este juntar avulso de pedaços ainda coerentes, porém já corroídos pela ausência do que estava antes ou vem depois, e contraditoriamente afirmando, na sua própria mutilação, um outro sentido fechado, definitivo, como é o que parecem ter as epígrafes postas à entrada de livros. A si mesmo pergunta se será possível definir uma unidade que abranja, como um colchete ou chaveta, o que é oposto e diverso..." (Saramago, 1988, p.65-66)
\end{abstract}

O lingüista, à semelhança de Ricardo Reis, rebusca na transcrição e na fita gravada os enunciados que o seduzem. Estuda os pedaços ainda coerentes, corroídos pela ausência do que estava antes ou vem depois, retorna à ode maior de onde foram extraídos, procura descobrir-lhes o sentido definitivo. A si mesmo pergunta se será possível explicar, como um colchete ou chàeta, o que é maleável e, portanto, diverso.

Este artigo é uma tentativa de captar o funcionamento das sentenças clivadas (daqui para frente SCs) no discurso semi-coloquial oral do Rio de Janeiro. Baseia-se na análise da amostra de fala de 17 (dezessete) cariocas $^{1}$ e compreende três partes: na primeira, caracterizo e exemplifico as referidas construções; na segunda, investigo a maneira como estas sentenças, principalmente as SENTENÇAS CLIVADAS PROPRIAMENTE DITAS (doravante CLIVs) podem sinalizar a estrutura tópica da seqüência discursiva em que ocorrem; na terceira, teço alguns comentários sobre o que me parecem ser as características mais gerais destas construções. A conclusão é apresentada na quarta parte.

Maria Luiza Braga. Professora da Universidade Federal Fluminense.

'As amostras de fala analisadas integram o acervo do Projeto Censo da Variaçåo Lingúistica do Rio de Janeiro. 


\section{1 - CARACTERIZAÇÃO DAS SENTENÇAS CLIVADAS}

No português falado no Brasil, coexistem seis tipos formalmente distintos de SCs. Estas variedades são rotuladas, descritas ${ }^{2}$ e exemplificadas abaixo.

\section{SENTENÇA CLIVADA PROPRIAMENTE DITA}

que

Ser $C 1$ quem $S-C^{1}$, em que $S-C^{1}=$ Sentença menos Constituinte.

Ex. (1)

I: $\mathrm{O}$ que você quer?

F: O que eu quero? Eu quero continuar estudando, sabe? Se der pra me formar, tudo bem, n'é? Se não der, eu ir arranjar uma coisa melhor pr: mim viver minha vida, eu sozinha, sabe? Sem ta sem ter que morar na

E: casa dos outros. ['É "isso que eu 'quero. $]^{3}$ [Hmhm.]

E: Os homens são sempre machóes?

\section{CONSTRUÇÕES É QUE}

$\mathrm{C} 1$ ser/ $3^{a}$ sg. que $\mathrm{S}-\mathrm{C}^{1}=$ Sentença menos Constituinte'

Ex. (2)

E: Mas você cozinha. E você deve ter algum prato que os seus fregueses gostam mais.

F: R

E: Oual é?

${ }^{2}$ Minha caracterizaçāo de SCs baseia-se na de Prince (1978), que substitui os termos foco e pressupasição por expressōes mais neutras: Constituinte e Sentença-Constituinte $^{1}$. O adjetivo focalizado e demais termos
correlatos, usados ao longo deste trabalho, são táo-somente sinônimos de ressaltado, salientado, posto em relevo, etc.

relevo, etc.

"Notaçöes:
Acento primário:"

Acento primário:"

Acento secundário:'

Pausa no meio do enunciado:

Pausa curta, isto é, pausa inferior a 1 (um) segundo, após a SC: (.)

Pausa longa, isto é, pausa superior a $1(\mathrm{um})$ segundo, após SC: (indicação dos segundos e de seus décimos entre parênteses)

Palavra interrompida: ,

Enunciado interrompido: - -

Risada: R

Entrevistador: $\mathrm{E}$

Entrevistado: $\mathrm{P}$

Participante: $P$

Entonação descendente:

Entonaçāo ascendente: ?
F: Ah, eu cozinho não. R A minha "tia é que 'cozinha. R.

E: E você náo sabe cozinhar nada?

F: Não, eu sei.

E:Hm. Qual [é o prato que você mais gosta] de fazer?

F: [Eu sei cozinhar]

Ah. eu gosto $\sim$ Bem, pra mim - p pra mim ... eu gosto assim muito de peixe,

\section{E: Hm.}

F: sabe?

(Jo 1154 B133)

\section{SENTENÇA PSEUDO-CLIVADA}

Quem

Oque

Ex. (3):

P: E quando o pelotão sai marchando, os garoto fica gritando: "Cavalo!"

$\mathrm{E}: \mathbf{R}$

F: Pior que é. Porque o - o pelotão tem que marchar assim (barulho com a mão, imitando o marchar do pelotão) [Com uma]

E:

[Marcando passo.]

F: É.

E: Não. É a $\sim$ À esquerda, n'é?

P: É. Com força. À direita [devagar.]

$\mathrm{E}$ :

[Devagar.]

P: Tam. Assim

E: Ham.

F: O CCE também entra assim, pra sentar.

$\mathrm{E}:$ E entra com bandeira também?

F: Entra. O pelotão, o CCE não.

E: $\mathrm{Hm}$.

P: 'Quem 'segura 'é o "Sandro. Ele segura, a gente segura a ponta da bandeira

$\mathrm{E}: \mathrm{O}$ que que você gosta mais na sua escola?

(RO/AP 317 A138)

\section{FOCO SER}

S-C ${ }^{1} S E R / 3^{a}$ sg. $C^{1}$, em que $S-C^{1}=$ Sentença menos Constituinte'.

Ex. (4):

F: Eu acho isso é uma boa, mesmo. Uma boa! A mulher deve ser independente, nunca depender do marido. 
E: Eh, mas às vezes os homens ficam muito ameaçados, os homens maridos.

$\mathrm{F}$ : Ah, eles ficam ameaçado nada. 'Eles 'ficam $\mathrm{eh}=\ldots e^{-}$"enciumados.

E: Pois é, nesse sentido [ $(\mathrm{X})]$

F:

['Eles 'ficam ] 'é com "ciúmes, porque

tem mulher que ganha mais do que o marido.

E: $\mathrm{Hm}$.

F: Conheço muito. Muita mulher que ganha mais do que marido e eles ficam enciumados, porque eles querem sempre ser os machões, n'é?

(MA 446 A235)

\section{QUE FOCO}

$\mathrm{C}^{1}$ que S- $\mathrm{C}^{1}$, em que S- $\mathrm{C}^{1}=$ Sentença menos Constituinte'.

Ex. (5):

F: Já teve três desfiles esse ano da Pluft. Eu vi um deles (X).

E: Mas aí são pessoas de fora que vêm desfilar aqui?

F: Não, são pessoas do Barramares [que são as convidadas.]

E: [Ah, são?]

F: Eu já até fui, mas eu não quis desfilar, porque eu não tenho jeito.

E: Hm.

F: Mas são pessoas que são convidadas, ou até elas se falam ... quem até Até uma das garotas da nossa... do nosso pessoal é mãe da organizadora do desfile - do desfile da Pluft. "Ela que 'organiza os desfiles aqui. Então ela chama todo mundo.

\section{E: Hmhm.}

(.)

F: Mas eu não tenho jeito pra desfilar. Aí eu não desfilo não. Eu assisti [esse desfile.]

E: [Mas você gosta de assistir.]

(GU 1889 B439)

\section{DUPLO FOCO}

$\operatorname{Ser} / 3^{a}$ sg. $\mathrm{C}^{1} \operatorname{ser} / 3^{a}$ sg. que $\mathrm{S}-\mathrm{C}^{1}$, em que $\mathrm{S}-\mathrm{C}^{1}=$ Sentença- Constituinte1. Ex. (6):

F: ... mas o caso é o seguinte: tu já viu país sendo governado por militar, rapaz? Qual o país que é bom? Qual? Nenhum. Tu não vê? Até o país lá de fora, sendo governado por militar, tu não vê que eles tão em uma boa. Eles estão tudo caindo. Mas comandado por civil, tu vê que ele tá bem. Porque acontece muito. O rombo tá muito grande $(\mathrm{X})$... O rombo é muito grande. Então pa eles tentar fechar, quem sofre é a gente, rapaz! É a "gente é que 'sofre. Gasolina subindo todo dia! Todo dia a gasolina sobe agora! Já ta cento e quarenta e cinco. Aumentou agora a semana passada. Tem condição?

(JA 1547 B735)
A distribuição dos constituintes é critério necessário, mas não suficiente à identificação de uma sentença clivada. Igualmente relevantes săo o padrão entonacional, a localização do acento primário e a função do elemento focalizado. Estas construções tendem a apresentar contorno entonacional descendente ${ }^{4}$, acento primário no constituinte focalizado e a ser formadas por uma única unidade entonacional, aqui definida como "a stretch of speech, by one speaker, occurring under a single coherent contour" (Chafe, 1988). A presença do auxiliar ser e/ou do pronome relativo, a envolver total ou parcialmente o Constituinte ${ }^{1}$, conjugada à localização do acento primário neste mesmo constituinte levam à sua focalização, simultaneamente autorizando, em enorme número de casos, uma leitura contrastiva da SC.

É o conjunto das propriedades referidas acima que permite distinguir o enunciado sublinhado em (7) de uma verdadeira CLIV. A análise do contexto maior em que ocorreu este enunciado, bem como dos gaguejos e hesitações claramente audíveis na fita, sugerem que o falante experimentava algumas dificuldades ao produzir este trecho. O que ele parece ter querido transmitir é que o Zico, jogador de futebol, tivera garra, tendo sido o que mais reclamara no time.

Ex. (7):

F: Ele teve garra... aquele pênalti roubado, que rasgaram a camisa dele -

E: Sacanagem, não?

F: Então. Re - 'Foi o 'time que 'mais "reclamou Ele foi o que mais levou o time a trente, sabe?

(ZR465 A175)

Neste trabalho, restringir-me-ei a três dos tipos caracterizados acima: sentença clivada propriamente dita (daqui para frente CLIV), sentença pseudo-clivada (daqui para frente PC) e construçōes É QUE. Distinguem-se eles quanto à classe de palavra e quanto à função sintática do Constituinte $^{1}$, consoante mostro nas Tabelas $1 \mathrm{e} 2$, respectivamente.

A leitura horizontal das percentagens apresentadas abaixo evidencia que substantivos, locuções prepositivas, pronomes pessoais e demonstrativos podem ocupar a posição de Constituinte ${ }^{1}$ nos três tipos de sentenças clivadas. A leitura vertical contrabalança, todavia, tal afirmação: substantivos e pronomes demonstrativos distribuem-se quase complementarmente em PCs e CLIVs, como se a classe preponderantemente ressaltada por um destes tipos de SC fosse relegada ao ostracismo no caso da outra variedade de construção clivada. As construções É QUE distinguem-se das anteriores, visto que aqui advérbios, substantivos e pronomes pessoais

${ }^{4}$ Exceto as que ocorrem como perguntas, cujo contorno torna-se, então, ascendente.

Organon 18/1991 
TABELA 1

Classe de palavras e tipos de sentenças clivadas.

\begin{tabular}{lrrrrrr}
\hline & \multicolumn{2}{c}{ PC } & \multicolumn{2}{c}{ CLIV } & \multicolumn{2}{c}{ É QUE } \\
& $\mathrm{F}$ & $\%$ & $\mathrm{~F}$ & $\%$ & $\mathrm{~F}$ & $\%$ \\
Substantivo & 23 & 56,0 & 5 & 12,0 & 19 & 31,5 \\
Cláusula & 7 & 17,0 & & & 5 & 8,5 \\
Loc. preposic. & 7 & 17,0 & 5 & 12,0 & 5 & 8,5 \\
Pron. pessoal & 3 & 7,5 & 8 & 20,0 & 11 & 18,5 \\
Pron. demonst. & 1 & 2,5 & 22 & 52,5 & 2 & 3,0 \\
Advérbio & & & 2 & 4,5 & 18 & 30,0 \\
TOTAL & 41 & 100,0 & 42 & 100,0 & 60 & 100,0 \\
\hline
\end{tabular}

apresentam índices não polarizados de ocorrência. Depreende-se, pois, da tabela acima que os vários tipos de SCs divergem quanto aos elementos que podem ser focalizados. Mesmo em referência às categorias de palavras que, em princípio, podem coocorrer com qualquer tipo de SC, é possível identificar uma distribuição preferencial.

Apresento, a seguir, os resultados para a função sintática do Constituinte 1 .

TABELA 2

Função sintática do constituinte:

\begin{tabular}{llrrrrr}
\hline & \multicolumn{2}{c}{ PCs } & \multicolumn{2}{c}{ CLIVs. } & \multicolumn{2}{c}{ É QUE } \\
& F & $\%$ & F & $\%$ & F & $\%$ \\
Sujeito & 41 & 100,0 & 21 & 50,0 & 27 & 45,0 \\
Circunstância & & & 14 & 33,5 & 26 & 43,5 \\
Objeto direto & & & 7 & 16,5 & 4 & 6,5 \\
Tópico frasal & & & & & 3 & 5,0 \\
TOTAL & 41 & 100,0 & 42 & 100,0 & 60 & 100,0 \\
\hline
\end{tabular}

Com relação a funções sintáticas, o perfil de cada sentença clivada, apenas esboçado quando da investigação da categoria gramatical, ganha contornos mais precisos e específicos. Assim, PCs 'focalizam' tão somente sujeitos; CLIVs, sujeitos, circunstâncias e objetos diretos; a estas três categorias, É QUE acrescenta um novo domínio: o tópico frasal.

A maneira como os números foram apresentados e comentados poderia sugerir semelhanças inexistentes entre CLIVs e É QUE no que diz respeito a circunstância. Convém esclarecer, todavia, que os advérbios que ocorrem em É QUE são aqueles que normalmente tendem a aparecer à esquerda das sentenças (Braga e Botelho, 1983), o que não é verdadeiro em referência às locuções prepositivas das CLIVs: aqui são as motivações discursivas que levam as referidas locuções à posição mais à esquerda do relativo. Para os objetos diretos, não se coloca tal diferenciação, pois, em ambos tipos de sentenças, a sua posição mais à esquerda parece decorrer de estratégias discursivas similares. ${ }^{5}$

A última tabela evidencia que, também quanto à função sintática do Constituinte ${ }^{1}$, os diversos tipos de SCs tendem a divergir. Embora sujeito seja a posição mais freqüentemente associada a tais construções, PCs opõem-se às demais por admitir apenas esta posição, enquanto É QUE e CLIVs apresentam uma gama mais diversificada de constituintes potencialmente ressaltáveis.

Caracterizadas e exemplificadas as SCs, passarei a seu papel na estruturação do tópico/subtópico discursivo da seqüência em que aparecem.

\section{2 - TÓPICO DISCURSIVO, MUDANÇA DE TURNO, PAUSA E SENTENÇAS CLIVADAS}

O escrutínio das SCs sugeria que, embora potencialmente todas pudessem funcionar como sentenças tópicas, isto é, todas fossem suscetíveis de exprimir diretamente as proposições tópicas (Van Dijk, 1977), as CLIVs pareciam particularmente bem adaptadas ao desempenho de tal tarefa. Á proporção que se esboçava o perfil desta variedade de SC, cristalizavam-se as indicações de que elas serviam basicamente à sinalização de fim de subtópico discursivo e de potencial mudança de turno.

Visando, pois, a captar a correlação das SCs quer com a estrutura tópica/subtópica da seqüência discursiva em que ocorriam, quer com o sistema de troca de turno, propus dois grupos de fatores ${ }^{6}$ a serem considerados a seguir. Vale lembrar que trabalhar a noção de tópico/subtópico discursivo em dados empíricos é tarefa repleta de artimanhas. O desenvolvimento discursivo, com seus fluxos e refluxos, a ausência de marcas formais que assegurem uma delimitação incontroversa dos subtópicos de que se tece o texto foram as principais dificuldades que enfrentei. Por fím, o próprio caráter pré-teórico da noção de tópico discursivo (Brown e Yule, 1983), problematiza ainda mais o seu manuseio.

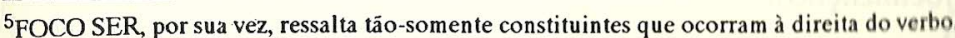

${ }^{6}$ No decorrer deste trabalho, empregarei os termos fatores e, ocasionalmente, grupo de fatores. Faço 0 per comodidade. Seu uso náo implica a utilizaçāo da metodologia da Teoria da Variaçáo, embera sua in. fluência seja evidente.

Organon $18 / 1991$ 
O tópico discursivo foi caracterizado, segundo Van Dijk:

"A concept or a conceptual structure (a proposition) may be come a discourse topic if it hierarchically organizes the conceptua (propositional) structure of the sequence" (1983, p.134). Ou ainda: "We have reconstructed the notion of topic of (a part'of) a discourse as a proposition entailed by the joint set of propositions expressed by the sequence" (1983, p.136).

Com o objetivo de capturar o desdobramento tópico, decidi trabalhar com a noção de subtópico discursivo (tópico atomístico), conceito também presente na obra de Van Dijk, mas melhor desenvolvido em Keenan e Schieffelin (1976), e Gardner (1987).

As decisões referentes ao sistema de turno, também delicadas, serão abordadas após as considerações sobre a estruturação tópica/subtópica.

Na tentativa de fotografar o papel das SCs na organização do tópico discursivo, propus doze diferentes fatores (mudança de tópico, mudança de subtópico, repetição do conteúdo proposicional da SC pelo entrevistador, questionamento do conteúdo proposicional da SC pelo entrevistador, refocalização pelo falante, etc.) que levaram a uma grande fragmentação dos resultados, obscurecendo o retrato que desejava nítido. Optei, então, por amalgamar e distribuir os dados em dois grandes subgrupos, consoante houvesse ou não mudança de subtópico (ou de tópico). A seguir, descrevo e exemplifico as categorias com que trabalhei.

(1) Introdução de novo subtópico/tópico, quer pelo entrevistador (exemplo 1), quer pelo falante (exemplo 8 abaixo).

Ex. (8):

E: Hum! Quem foi seu par?

F: Foi o Não! Era mulher e mulher. Ela botou [mulher e mulher].

E: [Ah! Era]

F: mulher com [mulher!]

S: [É]. Eu gosto mais de uma (garota) Janaína. Aí eu escolhi

eu pedi a tia pra ela me botar uma par para mim que seja a Janaína.

E: Hmhm.

F: Tem uma Janaína loura e R outra assim R, com cabelo escuro e morena. Foi a com cabelo "escuro e "morena que eu 'dancei com ela. (.)

F: Aí, quando foi na dança, sabe? um garoto, ele sobrou. Todo mundo foi dançando com o par, aí sobrou ele. Aí: "Cadê meu par?

(MAR 102 A053).

(2) Retomada de um subtópico, pelo falante, após digressão finalizada pelo $S C$ (refocalização).

Ex. (9).

F: Porque a outra, eu namorei a Suely dez ou doze anos, a Suely nunca quis. - Tirou duas criança. O primeıro houve um probleminha, ela teve que ti- rar. Tudo bem, eu tive que aceitar, na época eu sofri à beça, tava com uns vinte e um ano. Eu sofri muito. Mas já o segundo não. Fez, não me falou nada, quando eu vim a saber já tinha feito. Então acho que desde o mo mento que ela fez isso, não tomou nenhuma... assim, não teve consideração nenhuma comigo, n'é? Porque ela pra fazer, tinha que falar comigo. Não falou. E eu - E eu que sempre quis assumir, n'é? um compromisso com ela. 'Ela é que 'sempre me 'dava uma 'volta.

\section{$(\cdot)$}

Então eu achei que aquilo foi demais. E continuamos por mais algum tempo assim mas não deu pra levar o barco muito adiante, não. Aí começou briga, briga, briga.

(DA2110 B460)

(3) Repetição do conteúdo proposicional da SC, pelo entrevistador ou pelo falante, como exemplifico em (10) e (11), respectivamente.

Ex. (10):

E: Que que você sonha para sua filha? Não que você queira que ela seja, n'é?

F: Sabe que que eu quero que ela seja?

E: Hm.

F: Que eu estou sonhando? R Miss Brasil dois mil R

E: $R$

$\mathrm{F}: \mathrm{R} E$ ' "isso que eu 'quero para ela $\mathrm{R}$. (2.35)

E: R Hm. Barato R. E então Miss Brasil dois mil, n'é?

(DA 321 A123)

Ex. (11):

$\mathrm{E}$ : Você joga mais com seu irmão?

F: É. [jogo mais].

E: [Quem é que] (X)?

F: "Quem que me 'ensinou' foi = o 'cara 'lá da 'minha "avó.

$\mathrm{o}$ 'garoto. Ele que me ensinou.

E: Que garoto?

(VI 855 A396)

(4) Questionamento do conteúdo proposicional da SC.

Confira ex. (2)

(5) Desenvolvimento do subtópico discursivo após a SC.

Ex. (12):

E:A senhora ra senhora quando casou, a senhora já sabia cozinhar ou aprendeu na vida? 
F: Não, minha filha, naquele tempo, a gente casava sabendo cozinhar, lavar $\mathrm{R}$ passar, cuidar de criança... Eu sou a mais velha de cinco, agora já viu que eu sempre é que ajudava a minha mãe, n'é?

F: E a penúltima é que é mulher.

$$
\text { (.) }
$$

$$
\text { (.) }
$$

F: Entâo, foi vindo homem, homem, homem, homem e "eu é que oh (gesto) 'cuidava 'deles

F: N'é? Fazia todo o serviço de casa. Era limpeza -E aquilo era obrigação da gente.

E: Hm.

F: Não era dizer que fazia porque queria fazer, não. A gente não gostava, é lógico.

(HE 434 A247)

Os fatores 1 e 2, visto fazerem "avançar" o desenvolvimento tópico, valendo-me da metáfora de Firbas (1964), foram agrupados sob o rótulo de [+ mudança]. Já os demais foram considerados como exemplos de [mudança]. Desnecessário ressaltar que a última categoria, mesmo não provocando o "avançar" tópico, pode ser igualmente importante, contribuindo para a construção e desnudamento de significados interacionais relevantes. Ainda quanto aos fatores incluídos na última categoria, vale lembrar que repetição ou solicitação de confirmação do conteúdo proposicional do enunciado anterior (oito ocorrências) são estratégias mais comuns do que questionamento do referido conteúdo proposicional (duas ocorrências).

Os resultados para este grupo de fatores são apresentados a seguir.

TABELA 3

Sentenças clivadas e estruturação tópica.

\begin{tabular}{lrrrrrr}
\hline & \multicolumn{2}{c}{ PCs } & \multicolumn{2}{c}{ CLIVs } & \multicolumn{2}{c}{ É QUE } \\
& F & $\%$ & F & $\%$ & F & $\%$ \\
[+ mudan.subtóp]) & 15 & 36,5 & 30 & 71,5 & 29 & 48,5 \\
[- mudan. subtóp] & 26 & 63,5 & 12 & 28,5 & 31 & 51,5 \\
TOTAL & 41 & 100,0 & 42 & 100,0 & 60 & 100,0
\end{tabular}

Os números acima mostram uma harmoniosa distribuição, com PCs e CLIVs ocupando as posições extremas do contínuo cadeia tópica e CONSTRUÇÕES É QUE ocorrendo em posição intermediária. Em outras palavras, enquanto as CONSTRUÇÕES É QUE tendem a neutralizar a oposição entre [+ mudança] e [- mudança], as CLIVs tendem a favorecê-las e as PCs, a desestimulá-las.
Tal padrão distribucional correlaciona-se à relativa especialização funcional de cada tipo de SC. O fato de É QUE prestar-se primordialmente à expressão de contraste e de $\mathrm{PC}$ facilitar quer a introdução de referentes novos, quer a apresentação de "verdades gerais", explica as percentagens observadas acima. As CLIVs, por sua vez, embora possam exprimir contraste, são empregadas primordialmente na estruturação tópica/subtópica.

Mecanismos outros podem igualmente indicar fim de tópico/subtópico. Roncarati (1990), por exemplo, mostrou que mudanças de tópico/subtópico são mais prováveis do que a manutenção após reiteração de enunciados. Paredes Silva analisou as expressões constituídas por ser + pronome demonstrativo com referência estendida como elementos que "costuram" o texto, "arrematando-o" ou funcionando como "gancho". Com referência à primeira função, esclarece:

"Elas funcionam para o tópico discursivo como a coda de Labov para a narrativa. Ao procurar estabelecer as etapas de uma narrativa plenamente desenvolvida, Labov identifica a coda como a etapa final, que assinala seu término. É o momento da narrativa em que náo faria sentido uma pergunta como "E então o que aconteceu"? Ela dá ao ouvinte uma sensação de completude. Ali acabou uma etapa. Na fala, pode servir para indicar que é a vez do outro falar (a mudança de turno). No português essa função aparece cristalizada na expressão $E$ isso aí" $(1985, \mathrm{p} .6)$.

As CLIVs tendem a combinar estes dois procedimentos: recuperação da informação de uma seqüência prévia através da referência estendida do pronome demonstrativo (Halliday e Hasan, 1967) e reiteração do verbo (e de outros constituintes, porventura presentes) de um enunciadu anterior (cf. exemplo 1). A conseqüência desta junção de estratégias é a intensificação da faculdade sinalizadora de potencial fim de tópico/subtópico. Em se tratando de gênero narrativo, estas construções funcionam como codas, como exemplifico abaixo.

Ex. (13):

E: $\mathrm{R}$ Como é que é $\mathrm{R}$ ?

F: Foi! A moça levantou do caixão e se sentou. Pegou, tiraram todo mundo de lá. Daí veio um médico... Estava cheio de polícia lá. Veio um médico,

daí o médico Daí acho que mandaram dar injeção na moça pra moça morrer, daí a moça - daí enterraram a moça de novo. Foi "isso que 'aconteceu.

(.)

Olha, eh $=\sim \sim$ Na morte da mãe da minha cunhada..

(RO 1691 13354) 
Evidências adicionais a favor da interpretação proposta aqui são fornecidas pela análise do sistema de troca de turnos e da ocorrência de pausas após as SCs. Zimmerman (com. pes.) sugeriu-me que, em decorrência do caráter rígido de alocação de turnos em entrevistas, as CLIVs poderiam estar, simultaneamente à indicação de fim de subtópico, sinalizando lugar potencial de mudança de turno. Em outras palavras, o falante, ao assinalar o cumprimento da tarefa verbal que lhe fora solicitada, também insinuaria que o entrevistador poderia retomar a palavra. CLIVs atuariam, pois, no domínio da estruturação tópica e domínio do sistema de turno.

Para investigar o mecanismo de troca de turno, propus três fatores:

(1) Troca de turno após a emissão da SC.

Em referência a este fator, algumas considerações são necessárias. Aqui a dimensão e complexidade do turno tornam-se irrelevantes, isto é, a categoria em questão engloba tanto o oferecimento ${ }^{7}$ de novos tópicos/subtópicos pelo entrevistador quanto a produção de solicitadores verbais ${ }^{8}$. Estas duas possibilidades são ilustradas, respectivamente, em (2), acima, e (14), a seguir.

\section{Ex. (14):}

F: Sabe que eu, Ana Paula, Sandro, todo mundo tem, mesmo que (se) que é pobre. To - toda turma da Quatrocentos e Um tem o que comer dentro de casa, não tem necessidade de ficar pedindo pão. E 'quem 'fica 'pedindo 'pão 'é "mendin= go, 'lá na 'porta.

\section{E: $\mathrm{Hm}$}

P: Mas a gente não tava ali pa pegar pão, a gente tava pa brincar.

F: Pa fazer bagunça.

(RO/AP 764 A375)

Outro aspecto diz respeito ao modo como este grupo de fatores e o anterior recortam a dimensão tópico/subtópico discursivo. O primeiro (SCs e estruturação tópica/subtópica) ignorava a fonte da mudança, procurando ressaltar tão-somente o papel das construções clivadas na organização e sinalização da estrutura tópica/subtópica. O segundo grupo inverte a perspectiva e procura captar a interação falante/entrevistador, obscurecendo a colaboração do entrevistador enquanto artífice também do desenvolvimento tópico/subtópico.

\footnotetext{
${ }^{7} \mathrm{Na}$ situaçăo de entrevista, embora o informante fale a maior parte do tempo, é o entrevistador que propóe perguntas, selecionando, de uma certa forma, os aspectos a serem abordados. Nas nossas entrevis as, todavia, algumas vezes o falante esquivou-se de discorrer sobre o tópico/subtópico proposto pelo en trevistador. Dai o emprego do termo oferecimento, umplicando que a construção do discurso é uma tarela social que supóe a colaboraçăo dos vários participantes.

Traduzi literaimente a denominaçáo empregada por Maynard \& Zimmerman (1984). Solicrièr designa qualquer emissão verbal.
}

(2) Ausência de resposta verbal por parte do entrevistador, após a SC.

Confira ex. (9).

(4) Outros: resposta verbal por parte do entrevistador, após um ou dois enunciados posteriores à SC em questão.

Confira ex. (11).

Os resultados são mostrados na Tabela 4.

TABELA 4

Sentenças clivadas e sistema de troca de turno.

\begin{tabular}{lrrrrrr}
\hline & \multicolumn{2}{c}{ PCs } & \multicolumn{2}{c}{ CLIVs } & \multicolumn{2}{c}{ EUE } \\
& $\mathrm{F}$ & $\%$ & $\mathrm{~F}$ & $\%$ & $\mathrm{~F}$ & $\%$ \\
[+ mudança] & 12 & 29,5 & 17 & 40,5 & 18 & 30,0 \\
[- mudança] & 25 & 61,0 & 23 & 55,0 & 36 & 60,0 \\
[outros] & 4 & 9,5 & 2 & 4,5 & 6 & 10,0 \\
TOTAL & 41 & 100,03 & 42 & 100,0 & 60 & 100,0
\end{tabular}

Os números revelam uma curva semelhante para PCs, É QUE e CLIVs, com uma percentagem mais elevada de [ - mudança $]$ por parte do entrevistador. Tais resultados eram predizíveis em vista de algumas das características das entrevistas que estou investigando, entre elas a orientação dada aos entrevistadores no sentido de refrear sua fala e estimular a produção verbal dos falantes. Nestas circunstâncias, era previsível que as percentagens para o fator 'mudança de turno' fossem relativamente baixas. Todavia se, após uma SC, ocorre troca de turnos, esta é mais provável no contexto de uma CLIV.

O grupo pausa compreende também três fatores:

(1) [-pausa ] - Nenhum silêncio perceptível segue-se à SC. A transcrição procura retratar tal comportamento apresentando o material posterior à SC sem nenhuma interrupção. Confira exemplo (3).

(2) [ + pausa ] - Este fator inclui quer as pausas longas, quer as pausas curtas, como exemplifico em (10) e (12), respectivamente.

(3) Outras ocorrências - Engloba os dados em que a pausa ocorre após uma unidade entonacional que se segue imediatamente à SC. Aqui há um "intervalo semântico" entre a SC e a pausa, como mostro no trecho seguinte. 
Ex. (15):

'Quem tá "muito por 'dentro 'é o 'Leonardo 'Jordão, 'esse que 'falou que 'era 'Fluminense.

(.)

No exemplo acima, a pausa aparece posteriormente à emissão do aposto, unidade entonacional distinta. Os resultados são apresentados a seguir.

TABELA 5

Pausas e sentencas clivadas.

\begin{tabular}{lcrrrrr}
\hline & \multicolumn{2}{c}{ PCs } & \multicolumn{2}{c}{ CLIVs. } & \multicolumn{2}{c}{ É QUE } \\
& Fs & $\%$ & Fs & $\%$ & Fs & $\%$ \\
[+ pausa] & 15 & 36,5 & 25 & 59,5 & 29 & 48,5 \\
[-pausa] & 26 & 63,5 & 16 & 38,0 & 27 & 45,0 \\
TOTAL & & & 1 & 2,5 & 4 & 6,5 \\
& 41 & 100,0 & 42 & 100,0 & 60 & 100,0 \\
\hline
\end{tabular}

Observa-se aqui um padrão distribucional bastante similar ao observado na Tabela 3, com PCs e CLIVs novamente ocupando as posições extremas e antagônicas e É QUE revelando pouca sensibilidade à variável em análise.

Chafe (1987), Pawley e Syder (1976), e Maynard (1980) têm mencionado que a ocorrência de pausas pode correlacionar-se a causas distintas, requerendo a sua compreensão análises empíricas cuidadosas. Vale lembrar, todavia, que, segundo o primeiro, em narrativas, as pausas que precedem mudanças de "grandes parágrafos orais' tendem a ser mais longas. Ponto de vista semelhante é defendido por Brown e Yule (1983). Maynard, mais recentemente, comenta que as pausas tendem a sinalizar fim de tópico e preceder mudança de turno. O fato de as pausas ocorrerem mais freqüentemente após as CLIVs não é aleatório, mas um reforço a favor da hipótese que vê tais construções como sinalizadoras de potencial fim de tópico e de potencial mudança de turno.

Na caracterização do papel das SCs, mormente das CLIVs, frisei o caráter potencial da mudança de tópico/subtópico e da mudança de turno. Tal caráter potencial é uma decorrência das próprias características da conversação. Por se tratar de atividade desenvolvida conjunta e interacionalmente, os interlocutores cooperativos negociarão, quer a mudança de turno, quer o término de uma seqüência tópica/subtópica. No caso das amostras de fala analisadas aqui, a situação ainda é mais delicada, já que cumpria manter um estado contínuo de fala. Nestas circunstâncias, da sinalização de fim de tópico/subtópico, via CLIV e pausa, não decorria automaticamente a introdução de um novo assunto a ser abordado ou a tomada do turno pelo entrevistador. Face ao silêncio após uma SC, social- mente constrangedor, numerosas vezes o falante procedeu à reiteração do conteúdo proposicional de um ou mais enunciados anteriores, só posteriormente engatilhando a almejada troca. A categoria Outros, nos dois últimos grupos de fatores, constituiu uma tentativa de refletir a situação de fala da forma mais aproximada possível.

Tendo investigado o papel das SCs na organização tópica/subtópica de um trecho, passarei às considerações finais.

\section{3 - CONSIDERAÇÕES FINAIS}

Ao interpretar os resultados da Tabela 3, referi-me às funçốes desempenhadas por cada tipo de SC e expliquei aqueles em termos destas. É importante frisar que a distribuição funcional é apenas preferencial. Significa isto, restringindo-me a CLIVs É QUE, que o último tipo pode desempenhar o papel habitualmente reservado àquelas e vice-versa. A título de ilustração, apresento dois exemplos:

Ex. (16):

E: E qual é o.. assim, o maior número de problemas, assim, que aparece, que as pessoas levam?

F: O maior número de problema, mais é lanternagem, n'é? que nego ta batendo mais do que coração assustado.

E: É?

F: É. Bate muito. Mecânica apare -sempre aparece. Problema de freio, motor ratiando, entendeu? Mas aparece muita lanternagem. 'Lanternagem é que tem "muita.

E: Como é que é? Motor ratiando, assim, como é que é?

(Ja 19 A009)

Aqui, após a enumeração de problemas relacionados a automóveis, o entrevistador solicita do falante uma passagem do geral para o particular, isto é, que este se restrinja a um dos membros. Observe que, após a CONSTRUÇÃO É QUE, segue-se uma pausa e mudança de turno. Observe-se também como esta construção reitera o enunciado imediatamente precedente.

No trecho a seguir, em que a falante descreve uma das apariçôes de ET, o contraste entre a língua utilizada por aquela personagem e o idioma empregado na representação do diálogo entre este e Elliot é estabelecido por uma CLIV.

Ex. (17):

F: Mas depois, quando ele foi dormir, foi deitar, apareceu ele (ET). Ele (II. liot) pensou que era outro. Aí ele: "Mam Ma Mar". Queria falar $\operatorname{tambom}$

Organon 18/1991 
de novo: "Ma Ma - Ma ". "Ah, é você!" Falando inglês também. Eu vou - - eu vou falar assim como a nossa voz, mas só que vai ser in Era "inglês E: Hmhm. que ele 'falou, ta?

(MAR 807 A399)

Este trecho ilustra também a possibilidade de, na combinação de duas seqüências discursivas, exprimir-se simultaneamente mais de uma proposição relacional (Mann \& Thompson, p. 1986), no caso, reiteração e contraste. Maleabilidade funcional parece ser então um dos traços das sentenças clivadas.

Tendo me referido à flexibilidade funcional das SCs, passarei à conclusão.

\section{4- CONCLUSÃO}

Neste artigo, considerei as Sentenças Clivadas produzidas no discurso semicoloquial oral do Rio de Janeiro. Inicialmente caracterizei-as e exemplifiquei-as. Mostrei que, além da disposição peculiar de constituintes, o contorno entonacional e a localização do acento primário no Constituinte 1, levando à sua focalização, são traços definidores destas construções.

A seguir, propus categorias que permitissem captar a estruturação tópica/subtópica dos trechos discursivos em que as SCs apareciam e indiquei como CLIVs podem ser utilizadas na sinalização de fim de subtópico discursivo. Revelei que esta interpretação se reforça pelos resultados de duas outras variáveis, mudança de turno e ocorrência de pausa.

Por fim, mostrei que a compreensão das SCs implica a aceitação da sua maleabilidade funcional. Este funcionamento, desconcertante para o analista, que não consegue descrevê-lo com fórmulas rígidas, é uma decorrência do maior grau de liberdade de que os interlocutores dispõem a nível discursivo e interacional.

Torno minhas as considerações de Ricardo Reis:

"Procurar cobrir com uma unidade estas variedades é talvez tão absurdo como tentar esvaziar o mar com um balde, não por ser obra impossível, havendo tempo e força não faltando, mas porque seria necessário, primeiramente, encontrar na terra outra grande cova para o mar, e essa já sabemos que a não há suficiente, tanto mar, a terra tão pouca (Saramago, 1988, p.66).

\section{REFERENCIAS BIBLIOGRÁFICAS}

BRAGA, M. L. \& BOTELHO, M. A. P. Advérbios: características e diferenças quanto a sua posição na sentença. In: Encontro Nacional de Lingüística, VII. Rio de Janeiro: PUC, 1983.

BROWN, G. \& YULE, G. Discourse Analysis. Cambridge: Cambridge University Press, 1983.

CHAFE, W. Cognitive constraints on information flow. In: R. (Ed.) Coherence and Grounding in Discourse. Philadelphia: John Benjamins, 1987.

FIRBAS, Jan. On defining theme in functional sentence analysis. In: Travaux Linguistiques de Prague. Prague: Academia, 1964.

GARDNER, R. The identification and role of topic in spoken interaction. Semiotica, v.65, p.124-141, 1987.

HALLIDAY, M. A. K. \& HASAN, R. Cohesion in English. London: Longman, 1976.

HALLIDAY, M. A. K. \& Hasan, R. Cohesion in English. London: Longman, 1976.

KEENAN, E. O. \& SCHIEFFELIN, B. Topic as a Discourse Notion. In: LI, C. (Ed). Topic and Subject. New York: Academic Press, 1967.

MANN, William C. \& THOMPSON, S. A. Relational Propositions in Discourse. Discourse Process, v.9, p.57-90, 1986.

MAYNARD, D. W. Placement of topic changes in conversation. Semiotica, v.30, p.263-290, 1980.

\& ZIMMERMANN, Don H. Topical Talk, Ritual and the Social Organization of Relationships. Social Psychology Quarterly, v.47, p.301-316, 1984.

PAREDES SILVA, Vera L. "É isso ar̂" - Verbo ser e demonstrativo em funçáo coesiva no português. Comunicação apresentada no X Encontro Nacional de Lingüística. PUC/RJ, 1985, Mimeo.

PRINCE, Ellen. A comparison of WH-clefts and IT-clefts in discourse. Language, v. .54, p. $.883-907,1981$.

RONCARATI, Cláudia N. S. Estruturas paralelas e combinação de cláusulas. Comunicação apresentada no IX Congresso Internacional da ALFAL. UNICAMP/SP, 1990. Mimeo.

SARAMAGO, José. O ano da morte de Ricardo Reis. São Paulo: Companhia das Letras, 1980.

STECH, Ernest L. The analysis of conversational topic sequence structures. Semiotica, v.39, p.75-91, 1982.

VAN DIJK, Teun A. Text and Context. London: Longman, 1977. 